\title{
EFICACIA DE FUNGICIDAS DE SÍNTESIS Y BIOLÓGICO EN BASE A TRICHODERMA HARZIANUM PARA CONTROLAR PATÓGENOS DE SEMILLAS DE SOJA
}

\author{
Crovo, V. $^{1}$ \& Clemente, G.E. ${ }^{1}$
}

\begin{abstract}
RESUMEN
Los patógenos presentes en semillas causan fallas en la germinación, afectan el rendimiento del cultivo e introducen enfermedades en nuevas zonas. El tratamiento de semillas es una estrategia de protección ampliamente utilizada. En este trabajo se realizaron experimentos in vitro en cajas de Petri para evaluar la eficiencia de diferentes fungicidas p.a. pyraclostrobin+metil tiofanato, p.a. thiram+carbendazim y p.a. metalaxil-M para controlar Cercospora kikuchii, Fusarium spp. y Phomopsis spp., patógenos prevalentes en semillas de soja del sudeste de la provincia de Buenos Aires. Además se compararon la eficiencia de un fungicida biológico p.a. Trichoderma harzianum y uno químico (p.a. fludioxonil+metalaxil-M+tiabendazol). Los fungicidas en base a thiram+carbendazim y a pyraclostrobin+metil tiofanato mostraron la mayor inhibición del crecimiento de patógenos estudiados. El biofungicida mostró mayor control que el fungicida fludioxonil + metalaxil-M+tiabendazol, para los tres patógenos. Este trabajo analiza y presenta alternativas útiles para el control de patógenos de semillas de soja. Palabras claves: Glycine max; Semillas; Fungicidas; Trichoderma harzianum.
\end{abstract}

\begin{abstract}
Efficacy of synthetic and biological fungicide with Trichoderma harzianum to control seedborne pathogens of soybean.

Seedborne pathogens cause germination failures, affect crop yield and introduce diseases into new areas. Seed treatment is a widely used strategy to protect them. In this work, in vitro test were performed to evaluate the efficiency of fungicides pyraclostrobin+thiophanate methyl, thiram +carbendazim and metalaxyl-M to control Cercospora kikuchii, Fusarium spp. and Phomopsis spp. (pathogens prevalent in the southeast of Buenos Aires province). Furthermore, the control efficiency of a bio-fungicide (i.a. Trichoderma harzianum) and chemical fungicide (i.a fludioxonil +metalaxyl-M+thiabendazole) was compared. Fungicides thiram+carbendazim or pyraclostrobin+thiophanate
\end{abstract}

1.- Facultad de Ciencias Agrarias, UNMdP. CP 7620. C.C. 726. Email: crovo.veronica@inta.gov.ar Manuscrito recibido el 28 de julio de 2015 y aceptado para su publicación el 19 de noviembre de 2015. 


\section{Crovo et al.}

methyl showed the greatest inhibition of pathogens growth. For the three pathogens, the bio-fungicide showed better control than the fungicide fludioxonil+metalaxyl-M+thiabendazole. This work analyzes and presents useful alternatives for controlling soybean seedborne pathogens. Keywords: Glycine max; Seeds; Fungicide; Trichoderma harzianum.

\section{INTRODUCCIÓN}

Las semillas de soja pueden portar patógenos que afectan su germinación. Altos porcentajes de infección de semillas con estos patógenos pueden comprometer el establecimiento y el rendimiento de los cultivos y facilitar la introducción de enfermedades en predios sin antecedentes de ellas. Especies del género Fusarium spp. y Phomopsis spp. (20), así como Cercospora kikuchii son patógenos prevalentes en lotes de semillas de soja del sudeste de la provincia de Buenos Aires (20). Fusarium spp. no solo afecta la germinación de soja cuando contamina semillas sino también cuando está presente en su ambiente natural, el suelo, causando pudrición de las semillas, tizón de plántulas y podredumbre de cuello y raíces (22). Por otro lado, especies del género Phomopsis spp. son responsables del Cancro de la soja, enfermedad que limita la producción del cultivo cuando las condiciones epidemiológicas favorecen su presencia $(9,19,21)$. Esta enfermedad afecta los rendimientos, pero sobre todo disminuye la calidad y el poder germinativo de las semillas (20). C. kikuchii, agente causal de la Mancha púrpura de la semilla, generalmente no reduce la germinación de semillas, pero pueden presentar menor vigor (9).

El tratamiento de semillas es una estrategia para proteger a las semillas y a las plántulas de plagas y enfermedades. Aunque durante muchos años se utilizaron productos químicos, y no se detectó resis- tencia de los patógenos de semillas a las moléculas de síntesis, actualmente existe una tendencia mundial a disminuir el uso de agroquímicos por sus potenciales efectos secundarios sobre la salud humana y el medio ambiente (16). Esta tendencia viene acompañada del aumento de uso de productos biológicos, como parte de una estrategia dentro del concepto de manejo integrado de enfermedades (1). En este campo, el género Trichoderma es uno de los agentes de control biológico más estudiado, por su habilidad de antagonizar con hongos fitopatógenos en condiciones naturales. Los principales mecanismos de biocontrol atribuidos a este género son el micoparasitismo, la competencia por espacio y nutrientes y la producción de metabolitos secundarios, tales como sideróforos, antibióticos y enzimas $(11,14,5)$.

Como micoparásito, Trichoderma sp. crece sobre los hongos fitopatógenos, y penetra en sus células, alterando y degradando paredes celulares, causando retracción de la membrana plasmática y desorganización del citoplasma $(14,17)$.

Cuando actúa como competidor, Trichoderma sp. posee alta velocidad de crecimiento y mediante la secreción de metabolitos de diferente naturaleza, frena o elimina a otros microorganismos $(14,17)$. Por otra parte, muchas cepas de Trichoderma producen metabolitos secundarios volátiles y no volátiles, algunos de los cuales inhiben el desarrollo de otros microorganismos con los que no tienen contacto físico. Es- 